\title{
Retroactive DNA analysis for sex determination and dystrophin gene by polymerase chain reaction with archived cytogenetic slides
}

\author{
Soo-Kyung Choi ${ }^{1,5}$, Jin-Woo Kim 1 , \\ So-Yeon Park', Young-Mi Kim ${ }^{1}$, Jin-Mee Kim ${ }^{1}$, \\ Hyun-Mee Ryu ${ }^{2}$, Jae-Sub Yang ${ }^{3}$ and \\ Song-Ro Yoon ${ }^{4}$ \\ 1 Genetic Research Laboratory, Samsung Cheil Hospital and Women's Healthcare \\ Center, Medical Research Institute, Sungkyunkwan University, Seoul 110-745, Korea \\ 2 Department of Obstetrics and Gynecology, Samsung Cheil Hospital and Women's \\ Healthcare Center, College of Medicine, Sungkyunkwan University, Seoul 110-745, \\ Korea \\ 3 Department of Molecular Biology, Taegu University, \\ Kyungsan 712-714, Korea \\ 4 Department of Forensic Biology, \\ National Institute of Scientific Investigation, Seoul 158-097, Korea \\ 5 Corresponding author: Tel, 82-2-2000-7680; Fax, 82-2-2278-4574 \\ E-mail, genelab@samsung.co.kr
}

Accepted 4 March 1999

Abbreviations: PCR, polymerase chain reaction; PABY, pseudoautosomal boundary region; SRY, sex-determining region of the $Y$ chromosome; $Z F Y$, zinc finger $Y$ region

\begin{abstract}
We describe a rapid and efficient diagnostic method for sex determination and the dystrophin gene by the polymerase chain reaction (PCR) using archived cytogenetic slides. Archived cytogenetic slides stored for about 4 years at room temperature were used. To confirm whether DNA analysis is possible using the archived cytogenetic slides, we extracted the DNA from the slides and amplified the $Y$ centromeric region (DYZ3), the $X$ centromeric region (DXZ1) and the exon 46 of the dystrophin gene. Of the 50 cases, 24 were peripheral bloods, 13 were amniotic fluid cells, 5 were chorionic villus samplings and 8 were cord bloods. The PCR related sex determination in 22 females and 28 males, showed $100 \%$ concordance with the results of chromosome analysis, and all cases showed positive band for the exon 46 of the dystrophin gene. Of the 50 cases of the archived cytogenetic slides, we were fortunate enough to obtain the fresh blood sample from one fetus whose karyotype showed $45, X[34] / 46, X,+\operatorname{mar}[145]$ to compare the results of the gDNA with that from archived cytogenetic slide. To confirm whether the marker chromosome was derived from $Y$
\end{abstract}

chromosome, we studied the six loci (PABY, SRY, RPS4Y (SY16, 17), ZFY, DYS14) on the short arm, one locus (DYZ3) on the centromere and one locus (DYZ1) on the long arm. Of the 8 loci studies, all PCR related $Y$ chromosome showed positive band from both gDNA obtained from cord blood and archived cytogenetic slides. We could conclude from the above results that the marker chromosome was derived from the $Y$ chromosome. We believe our experiment is rapid and efficient for studies of over 10 independent loci from a single slide which has been kept in storage for up to 4 years and that archival Giemsa-stained cytogenetic slide repositories represent valuable DNA resources for clinical and forensic studies.

Keywords: archived slide analysis, dystrophin gene, sex determination

\section{Introduction}

Since its introduction in 1985, the polymerase chain reaction $(\mathrm{PCR})$ has been applied for DNA analysis in research and clinical fields. PCR has enormous potential for single-cell genetic diagnosis, as it allows a single gene to be amplified more than a billionfold in a matter of hours rather than days (Erlich et al., 1991).

Recently, the demand is increasing for molecular analysis of genetic disease using archived Giemsa banded cytogenetic slides. Previous studies reported the feasibility of amplifying DNA target sequences by PCR from biopsied tissues or fixed cells on glass slides (Fey et al., 1987; Grant et al., 1995; Sago et al., 1996). Jonveaux (1991) used a long extraction procedure prior to amplifying a single DNA target sequence from unstained slides. Yap and McGee (1991) developed a method for amplifying DNA by PCR directly on the microscopic glass slides with cell cultured and smeared. Fey et al. (1987) amplified DNA from routine bone marrow slides stored up to 10 years at room temperature, and Sago et al. (1996) detected the point mutation from archived cytogenetic slide using the PCR and direct DNA sequencing. Since further molecular analysis is often needed for a patient who has had previous cytogenetic analysis, but is no longer able to provide a blood sample, there is a clear need for the development of techniques that would allow retrospective study of archived cytogenetic slides. Through our study, we determinated that for the analysis of genetic abnormalities in cases where the patient had already passed away or any sampling was not available for the DNA analysis, archival samples on the cytogenetic slide can 
be used. Nevertheless, it is now possible to reanalyze samples which have been stored prior to development of DNA analysis.

In this study, we took 50 archived cytogenetic slides which had been stored for 4 years at room temperature, even though cytogenetic procedure with acid treatment had been considered to depurinate the DNAs. For the ultimate purpose of applying the method clinically, we limited our PCR applied DNA analysis to X-linked recessive disorder muscular dystrophy patients who required both sex determination and detection of exon 46 deletion which is localized in the central hot spot region of the dystrophin gene. In addition, we also analyzed a fetus who was found to have marker chromosome through conventional karyotyping. To confirm whether the marker chromosome was derived from the $Y$ chromosome, we amplified 7 specific regions on the $Y$ chromosome with PCR to detect the deletion loci. We also performed PCR simultaneously in order to compare the results using the gDNA extracted from cord blood with that using DNA extracted from the archived cytogenetic slide.

\section{Materials and Methods}

\section{Extraction of DNA from archived cytogenetic slides}

Dried, hardened and archived cells on the slides could be removed intact if the cellular materials were first softened. The archived slides were soaked in xylene at room temperature for 6 days to remove the immersion oil. Giemsa stain on the slides was removed by destaining in $100 \%$ ethanol for 5 min three times. The cellular materials on archived slides were hydrated by soaking in $\mathrm{H}_{2} \mathrm{O}$ for 5 min three times. Afterwards, each slide surface was spread with $100 \mu$ l lysis buffer (10 mM Tris$\mathrm{HCl}$ [pH 8.3], $50 \mathrm{mM} \mathrm{KCl}, 1.5 \mathrm{mM} \mathrm{MgCl}_{2}, 0.001 \%$ gelatin, $0.5 \%$ Tween 20; Sago et al., 1996), covered with a 25 $\mathrm{mm} \times 55 \mathrm{~mm}$ rectangular piece of parafilm and left undisturbed for $15 \mathrm{~min}$ at $56^{\circ} \mathrm{C}$. After removal of parafilm, $200 \mu \mathrm{l}$ water was added to each slide and followed by careful scraping off of the softened cellular materials using a single edge surgical steel razor blade under the clean bench. Suspended cellular materials were collected into a $0.6 \mathrm{ml}$ microcentrifuge tube and centrifuged at $3,000 \mathrm{~g}$ for $5 \mathrm{~min}$. After discarding the supernatant, the cell pellets were resuspended in 200 $\mu \mathrm{g} / \mathrm{ml}$ proteinase $\mathrm{K}$ in $50 \mu \mathrm{l}$ lysis buffer by vortexing and incubated for $45 \mathrm{~min}$ at $56^{\circ} \mathrm{C}$. Proteinase $\mathrm{K}$ was inactivated at $95^{\circ} \mathrm{C}$ for $10 \mathrm{~min}$. By this method, extracted DNA samples were either used immediately for PCR or stored at $-80^{\circ} \mathrm{C}$.

\section{PCR analysis}

A $4 \mu \mathrm{l}$ aliquot of proteinase $\mathrm{K}$ digested cell extracts was added to a $20 \mu \mathrm{l}$ reaction mixture $(10 \mathrm{mM} \mathrm{HCl}-\mathrm{Tris}[\mathrm{pH}$ 8.3], $50 \mathrm{mM} \mathrm{KCl}, 2.5 \mathrm{mM} \mathrm{MgCl}_{2}, 400 \mathrm{mM}$ dNTPs, $2 \mu \mathrm{M}$ primers, and $1 \mathrm{U}$ Taq polymerase). The DYZ3 on $\mathrm{Y}$ chromosome centromere, the DXZ1 on X chromosome centromere and exon 46 of the dystrophin gene on a total of 50 archived slide specimens were amplified (Table 1). In one case of a mosaic fetus, we amplified seven loci, 5 (PABY, SRY, RPS4Y, ZFY, DYS14) on the short arm, one (DYZ3) on the centromere and one (DYZ1) on the Yq11-Yq12 junction region (Table 2, Figure 1 and 2). All target DNAs were denatured for $10 \mathrm{~min}$ at $95^{\circ} \mathrm{C}$, then underwent 30 cycles of denaturing at $95^{\circ} \mathrm{C}$ for $0.5-1 \mathrm{~min}$, annealing at optimal temperatures of each loci (Table 1 and 2) for 1-2 $\mathrm{min}$, and extension at $72^{\circ} \mathrm{C}$ for $1 \mathrm{~min}$. The final cycle of $10 \mathrm{~min}$ extension at $72^{\circ} \mathrm{C}$ was followed. All cycles were performed in a Perkin Elmer Thermal Cycler (TaKaRa Schuzo Co). After amplification, $5 \mu \mathrm{l}$ aliquots of amplifi-cation products were electrophoresed in $2 \%$ agarose gels and visualized under ultraviolet illumination following ethidium bromide staining. To avoid experimental errors, 50 samples were divide into 5 to 10 test groups. In all experiments, normal male and female controls and blanks were also studied as controls.

\section{Results}

Table 1. Sequences, annealing temperatures and product sizes of PCR for one region of the $Y$ chromosome (DYZ3), $X$ chromosome (DXZ1) and exon 46 of the dystrophin gene.

\begin{tabular}{llcc}
\hline Locus & Primer sequences & $\begin{array}{c}\text { Annealing } \\
\text { temp. (' }{ }^{\circ} \text { ) }\end{array}$ & $\begin{array}{c}\text { Product } \\
\text { size (bp) }\end{array}$ \\
\hline DYZ3 & 5' ATGATAGAACGGAAATATG 3' & 55 & 170 \\
& 5' AGTAGAATGCAAAGGGCTCC 3' & & \\
DXZ1 & 5' AATCATCAAATGGAGATTTG 3' & 58 & 130 \\
& 5' GTTCAGCTCTGTGAGTGAAA 3' & & \\
Exon 46 & 5' GCTAGAAGAACAAAAGAATATCTT 3' & 64 \\
\hline
\end{tabular}


Table 2. Sequence, annealing temperature and product size of PCR primers related to 8 Y-specific loci from the fetus's slide $(45, X[34] / 46, X,+\operatorname{mar}[145])$.

\begin{tabular}{|c|c|c|c|}
\hline Locus & Primer sequence & $\begin{array}{l}\text { Annealing } \\
\text { temp. }\left({ }^{\circ} \mathrm{C}\right)\end{array}$ & $\begin{array}{l}\text { Product } \\
\text { size }(b p)\end{array}$ \\
\hline PABY & $\begin{array}{l}\text { 5' CTGAGAGTGGAAGTGTCGCAG 3' } \\
\text { 5' GTACTACCTTTAGAAAACTAGTATTTTCCC } 3^{\prime}\end{array}$ & 55 & 1100 \\
\hline $\begin{array}{l}\text { SRY } \\
\text { (XES) }\end{array}$ & $\begin{array}{l}\text { 5' CCCGAATTCGACAATGCAATCATATGCTTCTGC 3' } \\
\text { 5' CTGTAGCGGTCCCGTTGCTGCGGTG 3' }\end{array}$ & 60 & 609 \\
\hline $\begin{array}{l}\text { RPS4Y } \\
\text { (SY16) }\end{array}$ & $\begin{array}{l}\text { 5' CCTGGTGCTTCTGTGAAAAA 3' } \\
\text { 5' TGAAAGGAGCATAGTCCTGC 3' }\end{array}$ & 63 & 210 \\
\hline $\begin{array}{l}\text { RPS4Y } \\
\text { (SY17) }\end{array}$ & $\begin{array}{l}\text { 5' CAGACGGAACTATCTCACAGG 3' } \\
\text { 5' GCTGAGAACAGTGCTAAGGG 3' }\end{array}$ & 63 & 329 \\
\hline ZFY & $\begin{array}{l}\text { 5' CGAATTCATACCGGCGAGAAGCCATACC 3' } \\
\text { 5' AAAGCTTGTAGACACATCGTTAGGG 3' }\end{array}$ & 60 & 735 \\
\hline DYS14 & $\begin{array}{l}\text { 5' CTAGACCGCAGAGGCGCCAT 3' } \\
\text { 5' TAGTACCCACGCCTGCTCCGG 3' }\end{array}$ & 62 & 239 \\
\hline DYZ3 & $\begin{array}{l}\text { 5' ATGATAGAACGGAAATATG 3' } \\
\text { 5' AGTAGAATGCAAAGGGCTCC } 3 \text { ' }\end{array}$ & 55 & 170 \\
\hline DYZ1 & $\begin{array}{l}\text { 5' TCCACTTTATTCCAGGCCTGTCC 3' } \\
\text { 5' TTGAATGGAATGGGAACGAATGG 3' }\end{array}$ & 62 & 149 \\
\hline
\end{tabular}
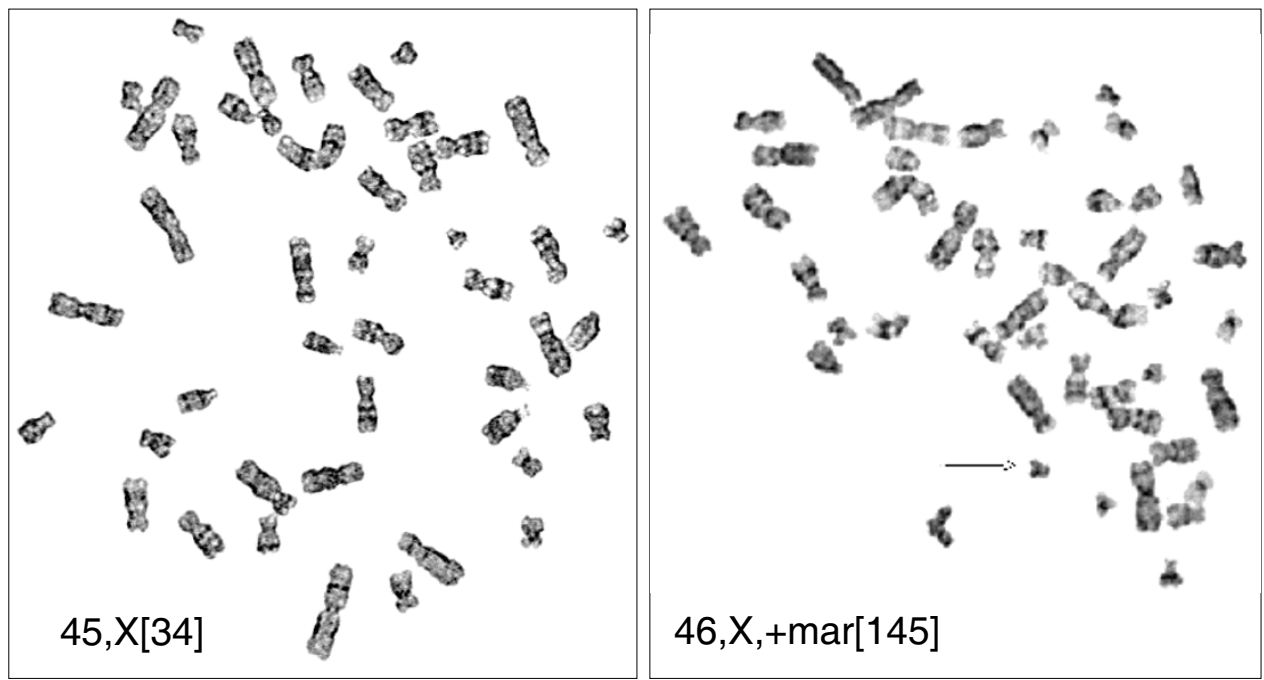

Figure 1. Giemsa stained metaphase from the fetus showing mosaicism with 45,X[34]/46,X,+mar[145]. The arrow indicates the marker chromosome.

Table 3. Breakdown of positive signals in DYZ3, DXZ1 and exon 46 of the dystrophin gene loci from cytogenetic archived slides according to sample source.

\begin{tabular}{lcccc}
\hline Locus & peripheral blood & amniocyte & chorionic villus & cord blood \\
\hline DYZ3 & 12 & 8 & 3 & $5^{\mathrm{a}}$ \\
DXZ1 & 23 & 13 & 5 & 9 \\
Exon 46 & 23 & 13 & 5 & 9 \\
\hline
\end{tabular}

a including a fetus karyotyped 45,X[34]/46,X,+mar[145] 


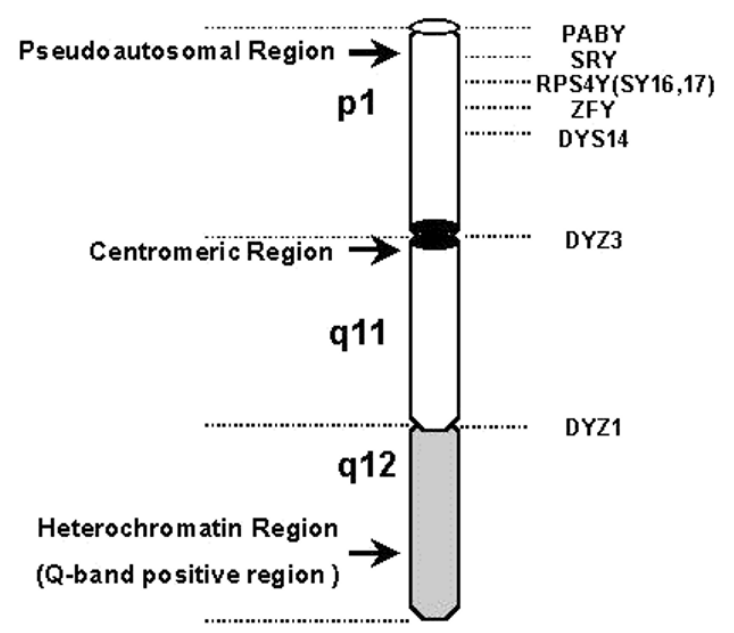

Figure 2. Diagram shows the $Y$ chromosome. Three major regions are shown on the left and 7 regions ( 8 loci) used in our studying on the right.

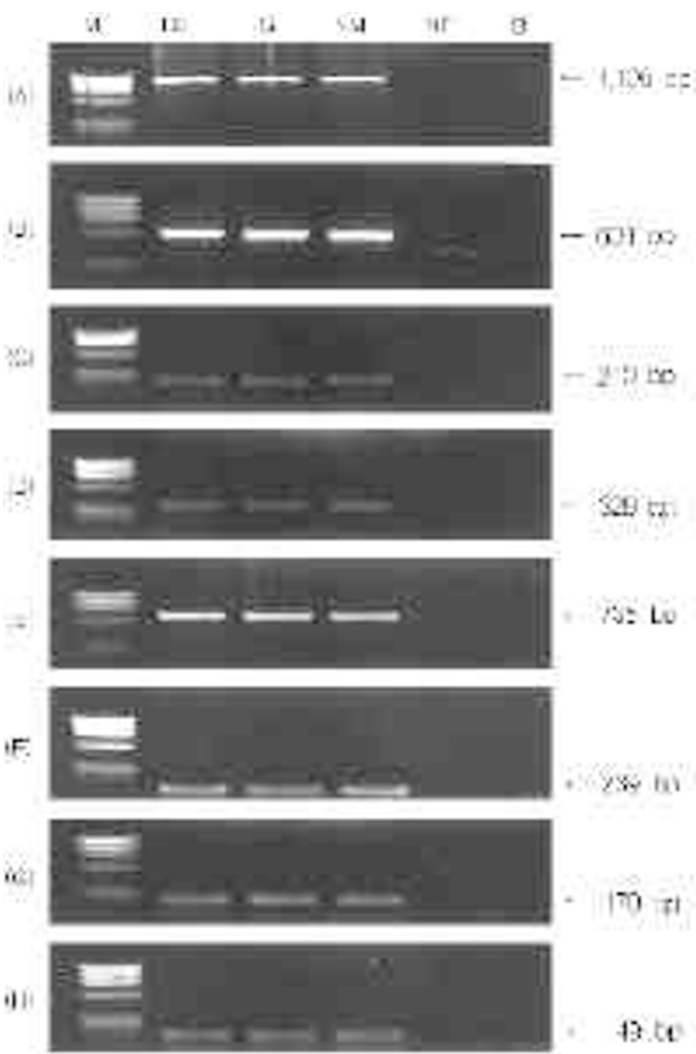

Figure 4. Electrophoretic analysis of PCR products for (A) PABY, (B) SRY, (C) RPS4Y: SY16, (D) RPS4Y: SY17, (E) ZFY, (F) DSY14, (G) DYZ3, and (H) DYZ1. [M: $\phi X 174-$ Haell marker, FS: fetal slide, FG: fetal gDNA, NM: normal male, NF: normal female, B: blank]

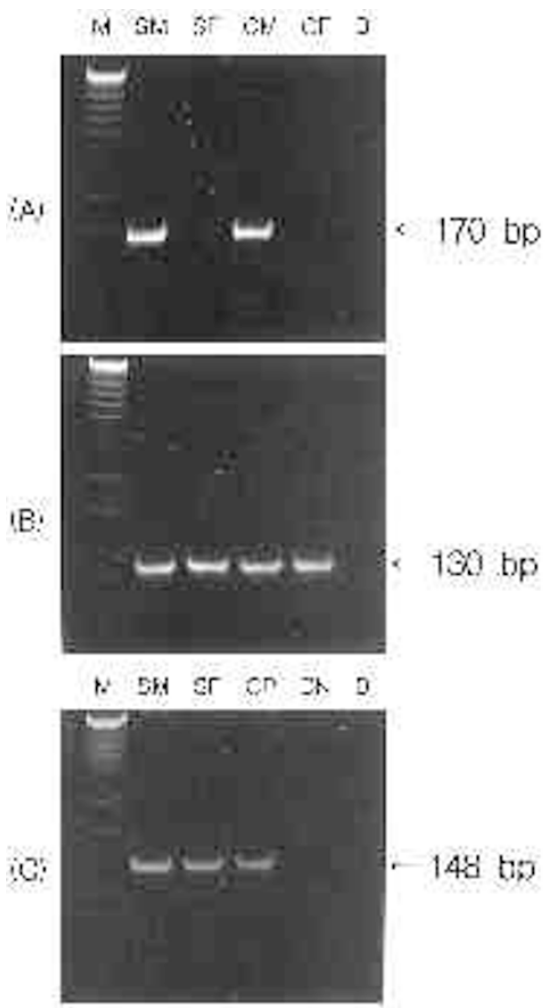

Figure 3. Electrophoretic analysis of PCR products for (A) DYZ3, (B) DXZ1 and (C) exon 46 of the dystrophin gene. [M: pGEM marker, SM: slide male sample, SF: slide female sample CM: control male, CF: control female, CP: control positive, CN: control negative, and B: blank]

PCR analysis was performed on the DNA extracted from 50 archived cytogenetic slides which were stored for about 4 years at room temperature. Of the 50 cases, 24 were peripheral blood, 13 were amniotic fluid cell, 5 were chorionic villus sell and 8 were cord blood. The reliability of our experiments for the amplification of the exon 46 of the dystrophin gene and X-specific locus (DXZ1) was obtained. Also, the $Y$ centromeric locus (DYZ3) was amplified for comparison with the chromosome study. The PCR results, 22 females and 28 males, were judged $100 \%$ concordance with the results of the chromosome analysis, and all the cases showed normal positive band for the exon 46 of the dystrophin gene (Table 3, Figure 3).

In case of a mosaic cord blood specimen which showed positive for the $Y$ centromeric region and revealed a mosaic karyotype 45,X[34]/46,X,+mar[145] cytogenetically, the marker chromosome was strongly suspected to be derived from $Y$ chromosome. To investigate this possibility, 7 loci on $Y$ chromosome were observed in both PCR reaction using the gDNA from cord blood and 
Table 4. Comparison of PCR analysis results in the archived slides and gDNA from fetus with $45, X[34] / 46, X,+$ mar[145]. All loci on the $\mathrm{Y}$ chromosome were represented for both.

\begin{tabular}{lccccccccc}
\hline & \multicolumn{10}{c}{ Y-specific locus } \\
\cline { 2 - 8 } & PABY & SRY & $\begin{array}{l}\text { RPS4Y } \\
\text { (ST16) }\end{array}$ & $\begin{array}{l}\text { RPS4Y } \\
\text { (ST17) }\end{array}$ & ZFY & DYS14 & DYZ3 & DYZ1 \\
\hline archived slide & + & + & + & + & + & + & + & + \\
gDNA & + & + & + & + & + & + & + & +
\end{tabular}

the DNA from the archived cytogenetic slide. The amplification of gDNA and slide DNA showed the same results that a fetus had 7 loci each on the $Y$ chromosome (Table 4, Figure 4). With PCR study, analysis was proposed that in this patient the marker chromosome that was derived from the $\mathrm{Y}$ chromosome. To exclude the possibility of false positive and negative cases, we included male, female and blank controls to each of our test groups. In the male control, we obtained the expected size of the amplificated products. And in the female and the blank, we could not, as expected. In conclusion, the results of the controls confirmed that our experiment was free of contamination and is reliable.

\section{Discussion}

Recently, with the development of better molecular analysis techniques, we were able to analyze DNA using a very small number of cells, and small amounts of paraffin embedded tissues, old stained archival slides, the blood stain, and the even the denatured aged-tissue samples. Especially among them, archival samples of the cytogenetic slide can be useful for the purpose of retrospective study for genetic abnormalities in cases where the patient had already passed away or further sampling was not available for the DNA analysis. Such researches have been previously done for genetic analysis from a biopsied tissues or cells fixed to glass slides (Fey et al., 1987; Grant et al., 1995; Sago et al., 1996). Attempts at isolating high molecular weight DNA from older material have been less successful than low molecular DNA (Higuchi et al., 1984).

Generally, to obtain successful PCR results, the primer sequence, the target size, and PCR amplification con-ditions are important for reliable amplification from old stained slides. In this experiment, target regions from 130 to 1,100 base pairs were amplified successfully using extracted DNA from slides which has been stored up to 4 years. Our experiment was limited due to the fact that no slides beyond the 4 years were available. Were older slides available, we would still have been able to obtain successful amplification regardless of age. The procedures of preparing the cytogenetic slides by fixing, staining, and archiving can minimize the contamination more effectively than others, fixed cells stick tenaciously to glass slides. In our experimental procedures, we have seen that none of our results were due to contamination and thus leading to false positive results.

Another use of cytogenetic archival slides for the similar purpose of our experiment is termed "slide PCR". The slide PCR amplifies the DNA directly on archival slides. Slide PCR provides an alternative for analysis of cell samples that are already on slides without the need for scrapping, and minimizing risk of contamination by manipulation (Yap and McGee, 1991). However, multi-target region analysis is not possible simultaneously with this method. To get around this limitation, we extracted the DNA from archival slides and performed 10 independent target-region analysis.

DNA fragments can be minimized with the treatment of the proteinase $\mathrm{K}$ with Tween-20 detergent in lysis buffer until cellular materials on the slide are loose (Sago et al., 1996). During the proteinase $\mathrm{K}$ digestion, we used parafilm in place of glass coverslips to prevent binding of DNA and evaporation. Also, parafilm is easily removable during the extraction of DNA from slides. Through the above the protocols, our PCR results for the sex determination were exactly the same as those of cytogenetic results. As for dystrophin gene, all samples were found to have the gene.

In case of one mosaic fetus whose karyotype showed $45, X[34] / 46, X,+\operatorname{mar}[145]$, we were able to obtain the cord blood gDNA for analysis and compare the results with the DNA from archival slides. As such, we could provide a DNA analysis using the archival slides to support the clinical diagnosis for a patient.

In our experiment, we were able to study over 10 independent target regions of the dystrophin and $\mathrm{X}, \mathrm{Y}$ specific regions. Although we used archival slides from abortues, fetuses, newborns, leukemic patients and adult samples which had been kept in storage for an extended period, we successfully amplified the archival DNA for sex determination and dystrophin gene study both rapidly 
and reliably with the DNA extraction. We believe that this method can provide a rapid and efficient genetic analysis when it is not possible to obtain the fresh samples, but have access to only archival cytogenetic slides from family members or the patient with genetic disease.

\section{References}

Ellis, N., Kidd, J., Goodfellow, P. J., Kidd, K. and Goodfellow, P. N. (1990) Strong linkage disequilibrium between the $\mathrm{XY} 274$ polymorphism and the pseudoautosomal boundary. Am. J. Hum. Genet. 46: 950-955

Erlich, H. A., Gelfand, D. and Sninsky, J. J. (1991) Recent advances in the polymerase chain reaction. Nature 252: 1643-1651

Fey, M. F., Pilkington, S. P., Summers, C. and Wainscoat, J. S. (1987) Molecular diagnosis of haematological disorders using DNA from stored bone marrow slides. Brit. J. Haematol 67: 489-192

Fisher, E. M., Beer-Romero, P., Brown, L. G., Ridley, A., McNeil, J. A., Lawrence, J. B., Wilard, H. F., Bieber, F. R. and Page, D. C. (1990) Homo-logous ribosomal protein genes on the human $X$ and $Y$ chromosome: escape from $X$ inactivation and possible implications for Turner syndrome. Cell 63: 1205-1218

Florentin, L., Mavrou, A., Kekou, K. and Metaxotou, C. (1995) Deletion patterns of Duchenne and Becker muscular dystrophies in Greene. J. Med. Genet. 32: 48-51

Grant, R. F., Malinak, C. J., Wu, H., Sabo, A. and Tsai, C. (1995) PCR amplification and DNA sequencing of SRV-2 from archived tumor tissues. Virus Research 36: 187-200

Jimenez, R., Sanchez, A., Burgos, M. and Diaz de la Guardia, R. (1996) Puzzling out the genetics of mammalian sex determination. Trends Genet. 12: 164-166

Jonveaux, P. (1991) PCR amplification of specific DNA sequences from routinely fixed chromosomal spreads. Nucl. Acid Res. 19: 1946

Liu, J., Lissens, W., Broeckhoven, C. V., Lofgren, A., Camus, Michel., Liebaers, I. and Steirteghem, A. V. (1995) Normal pregnancy after pre-implantation DNA diagnosis of a dystrophin gene deletion. Prena. Diagn. 15: 351-358

Manz, E., Alkan, M., Buler, E. and Schmidtke, J. (1992) Arrangement of DYZ1 and DYZ2 repeats on the human Y-chromosome's case with pre-sence of DYZ1 and DYZ2. Molecular and Cellular Probes 6: 257-259

Mastrangelo, P., Zwingman, T., Erickson R. P. and Blecher, S. R. (1994) ZFY is transcribed in the normal mouse epididymis and in the XXSxr testis. Dev. Genet. 15: 129138
McElreavey, K., Vilain, E., Abbas, N., Herskowitz, Y. and Fellous, M. (1993) A regulatory cascade hypothesis for mammalian sex determination: SRY represses a negative regulator of male development. Proc. Nat. Acad. Sci. USA 90: 3368-3372

Nagafuchi, S., Namiki, M., Nakahori, Y. Kondoh, N., Okuyama, A. and Nakagome, Y. (1993) A minute deletion of the $Y$ chromosome in men with azoospermia. J. Urol. 150: 1155-1157

Reijo, R., Alagappan, R. K., Patrizio, P. and Page, D. C. (1996) Severe oligozoospermia resulting from deletions of azoospermia factor gene on $\mathrm{Y}$ chromosome. Lancet 345 : 1290-1293

Sago, H., Goldberg, J. D. and Lebo, R. V. (1996) Point mutation analysis of archived cytogenetic slide DNA. Cytogenet. Cell Genet. 73: 343-346

Singh, V., Sinha, S., Mishra, S., Chatuvedi, L. S., Pradhan, S., Mittal, R. D. and Mittal, B. (1997) Proportion and pattern of dystrophin gene dele-tions in North Indian Duchenne and Becker muscular dystrophy patients. Hum. Genet. 99: 206-208

Stuppia, L., Mastroprimiano, G., Calabrese, G., Peila, R., Tenaglis, R. and Palka, G. (1996) Microdeletions in interval 6 of the $Y$ chromosome detected by STS-PCR in 6 of 33 patients with idiopathic oligo- or azoos-permia. Cytogenet. Cell Genet. 72: 155-158

Tyler-Smith, C. (1987) Structure of repeated sequences in the centromeric region of the human $Y$ chromosome. Development 101: 93-100

Vereb, M., Agulnik, A. I., Houston, J. T., Lipschultz, L. I., Lamb, D. J. and Bishop, C. E. (1997) Absence of DAZ gene mutations in cases of non-obstructed azoospermia. Mol. Hum. Reprod. 3: 55-59

Verma, R. S. and Babu, A. (1994) Human chromosome: principles and techniques. Chapter 3 Banding techniques. pp. 78-80, McGraw-Hill, U.S.A.

Yap, E. P. H. and McGee, J. O'D. (1991) Slide PCR: DNA amplification from cell samples on microscopic glass slides. Nucleic Acids Research 19: 4294

Zanaria, E., Muscatelli, F., Bardoni, B., Strom, T. M., Guioli, S., Guo, W., Lalli, E., Moser, C., Walker, A. P., McCabe E.R.B., Meitinger, T., Monaco A. P., Sassone-Corsi, P. and Camerino, G. (1994) An unusual member of the nuclear hormone receptor superfamily responsible for $\mathrm{X}$-linked adrenal hypoplasia congenita. Nature 372: 635-641 